\title{
Psicose Associada a Produtos de Ervanária: Perturbação Delirante Orgânica de Carácter latrogénico
}

\author{
Psychosis Associated with Herbal Products: latrogenic \\ Delusional Disorder
}

\author{
Ana Sofia MACHADO $\square^{1,2}$, Ana DIAS-AMARAL ${ }^{1}$, Alzira SILVA ${ }^{1,2}$, Rosa GRANGEIA ${ }^{1}$ \\ Acta Med Port 2021 Jul-Aug;34(7-8):548-551 - https://doi.org/10.20344/amp.13135
}

\begin{abstract}
RESUMO
Sintomas psicóticos podem constituir a forma de apresentação de alterações estruturais, metabólicas ou tóxicas. As perturbações delirantes orgânicas são caraterizadas pela presença de ideias delirantes com evidência de disfunção cerebral. A iatrogenia pode ser uma causa desta disfunção. Apresentamos um caso de sintomas neuropsiquiátricos, incluindo perturbação delirante, secundária ao uso de produtos de ervanária. A noção de inocuidade associada a estes produtos origina que o consumo dos mesmos não seja referido espontaneamente pelo doente na recolha da história clínica, pelo que a sua utilização deve ser ativamente questionada.

Palavras-chave: Delírios; Doença latrogénica; Extratos Vegetais/efeitos adversos; Psicoses Induzidas por Substâncias; Suplementos Nutricionais/efeitos adversos; Vitex
\end{abstract}

\section{ABSTRACT}

Metabolic, toxic or structural brain changes may present as psychotic symptoms. Organic delusional disorders are characterized by the presence of delusional ideas with evidence of brain dysfunction. latrogenesis may be a cause of this dysfunction. We present a case of neuropsychiatric symptoms, including delusional disorder, secondary to the use of herbal products. The patient's perception regarding the safety of natural products might result in an omission to report their use during clinical history taking, and thus its use should be actively questioned.

Keywords: Delusions; Dietary Supplements/adverse effects; latrogenic Disease; Plant Extracts/adverse effects; Psychoses, Substance-Induced; Vitex

\section{INTRODUÇÃO}

O termo 'secundária' ou 'orgânica' aplicado a uma perturbação delirante procura traduzir o surgimento de delírios na sequência de distúrbio da função cerebral recentemente adquirido. Este distúrbio pode dever-se a uma grande variedade de condições tóxico-metabólicas ou alterações neurológicas específicas. A disfunção primária reside no sistema límbico ou núcleos da base, locais onde se encontram projeções dopaminérgicas consideradas fundamentais nas perturbações psicóticas endógenas. ${ }^{1,2} \mathrm{O}$ estudo dos mecanismos associados às psicoses secundárias tem contribuído para o conhecimento da fisiopatologia e etiologia da psicose primária. ${ }^{3,4}$ Neste trabalho, apresentamos 0 caso clínico de mulher de 68 anos com consumo de produtos de ervanária que desenvolveu sintomatologia psicótica e alterações do comportamento que culminaram no seu internamento involuntário. Encontram-se na literatura vários relatos de quadros psicóticos ou maniformes relacionados com consumo de vários suplementos dietéticos. ${ }^{5-8}$ Estes preparados de substâncias naturais não se encontram regulados, desconhecendo-se quais os efeitos que poderão ter na saúde humana. Os utilizadores destes produtos procuram habitualmente melhoria de humor e da função cognitiva acreditando que o carácter 'natural' dos mesmos Ihes confere ausência de efeitos secundários. ${ }^{9}$

\section{CASO CLÍNICO}

Doente do sexo feminino, 64 anos de idade, reformada (cozinheira), casada, com duas filhas. Não apresentava antecedentes médicos ou psiquiátricos, pessoais ou familiares, relevantes. Em fevereiro de 2014, após falecimento da mãe, com quem não tinha contacto há vários anos, apresentou-se progressivamente mais triste e isolada. Em maio do mesmo ano, recorreu a uma ervanária e iniciou a toma diária de vários produtos, com o objetivo de "andar mais animada" (sic). Em junho, iniciou comportamentos bizarros e inéditos: defumou a casa porque dizia haver espíritos malignos e tentou defumar a campa da mãe no cemitério. Nessa altura, tinha períodos de desorientação temporo-espacial, discurso incoerente e agressividade dirigida à família. Foi levada ao Serviço de Urgência, onde se identificou um estado de mal epilético não-convulsivo (Tabela 1). É então internada na Unidade de Neurocríticos e, posteriormente, no Serviço de Neurologia, em agosto de 2014, onde permaneceu 14 dias, por suspeita de encefalite límbica. Efetuou estudo orgânico alargado de forma a identificar a possível etiologia das crises, o qual não revelou alterações (Tabela 2). Foi observada por Psiquiatria de Ligação, que assumiu a presença de alteração comportamental secundária a disfunção cerebral, tendo optado por não medicar com psicofármacos. Teve alta com o diagnóstico provável de encefalite tóxica, medicada com fenitoína $100 \mathrm{mg}$ tid e

\footnotetext{
1. Serviço de Psiquiatria. Clínica de Psiquiatria e Saúde Mental. Centro Hospitalar e Universitário de São João. Porto. Portugal.

2. Departamento de Neurociências Clínicas. Faculdade de Medicina. Universidade do Porto. Porto. Portugal.

$\triangle$ Autor correspondente: Ana Sofia Machado. anasofiamm7@gmail.com

Recebido: 22 de setembro de 2019 - Aceite: 27 de novembro de 2019 - First published: 18 de maio de 2020 - Online issue published: 01 de julho de 2021 Copyright $\odot$ Ordem dos Médicos 2021
} 
Tabela 1 - Estudo complementar efetuado na admissão no Serviço de Urgência

\begin{tabular}{|c|c|}
\hline Exame complementar & Resultado \\
\hline \multirow[t]{2}{*}{ Eletroencefalograma } & $\begin{array}{l}\text { Registaram-se três crises caracterizadas semiologicamente por interrupção da consciência e } \\
\text { pestanejo rápido, durando aproximadamente } 10 \text { minutos cada. No EEG, a alteração inicial é fronto- } \\
\text { temporal esquerda, com actividade teta rítmica máxima nas derivações fronto-temporais esquerdas } \\
\text { e linha média. Esta actividade recruta gradualmente regiões adjacentes (ipsi- e contralaterais) e } \\
\text { evolui em morfologia para ponta-onda, dupla ponta-onda e poliponta-onda rítmica (entre os } 2 \text { e os } \\
3,5 \mathrm{~Hz} \text { ). Perto do final, há uma transição para delta rítmico e o final caracteriza-se por uma atenuação } \\
\text { gradual de voltagens. Clinicamente, recupera rapidamente a consciência e responde adequadamente } \\
\text { a questões simples. }\end{array}$ \\
\hline & $\begin{array}{l}\text { Conclusão: Registo de três crises focais muito prolongadas com semiologia dialéptica e } \\
\text { correlação gráfica inicial fronto-temporal esquerda. Estes achados configuram estado de mal } \\
\text { não-convulsivo de origem focal. }\end{array}$ \\
\hline TC-CE & Sem alterações morfológicas. \\
\hline Hemograma & Normal. \\
\hline Bioquímica & $\begin{array}{l}\text { Função renal e hepática normal. lonograma (sódio, potássio, cloro, cálcio e fosfato) normal. Marcadores } \\
\text { inflamatórios negativos. }\end{array}$ \\
\hline
\end{tabular}

TC-CE: tomografia computorizada crânio-encefálica

Tabela 2 - Estudo complementar efetuado no internamento em Neurologia.

\begin{tabular}{ll}
\hline Exame complementar & Resultado \\
\hline RMN-CE & Integridade morfológica e de sinal das estruturas medianas. Não se observam alterações \\
& volumétricas, morfológicas ou de sinal dos hipocampos e estruturas peri-hipocampais. \\
& Ausência de alterações morfológicas ou das características de sinal do parênquima encefálico \\
supra e infratentorial.
\end{tabular}

TC cervico-toraco-abdomino-pélvico Não foram detetadas massas ou nódulos.

Função tiroideia

Normal.

Vitamina B12

Normal.

Ácido fólico

Normal.

Serologias VIH, VHC, VHB

Negativas.

Punção lombar

Exame citoquímico normal e serologias para CMV, HSV, VZV, enterovírus, West-Nile virus, Listeria, VDRL e micobactérias negativas

Estudo auto-imune

ANCA, ANA, atc anti-dsDNA, factor reumatóide, atc anti-tiroideus, atc anti-ENA (anti-Ro, antiLa, anti-Sm, anti-Scl70, anti-Jo1) negativos.

Atc anti-neuronais negativos.

Atc anti-NMDA, anti-AMPA, anti-LGI1 negativos.

RM-CE: ressonância magnética crânio-encefálica; TC: tomografia computorizada; VIH: vírus da imunodeficiência humana; VHC: vírus da hepatite C; VHB: vírus da hepatite B; CMV: citomegalovírus; HSV: herpes simplex vírus; VZV: varicela-zoster vírus; VDRL: venereal disease research laboratory test; ANCA: anticorpos anti-citoplasma do neutrófilo; ANA: anticorpos anti-nuclear; atc: anticorpos; dsDNA: ácido desoxirribonucleico de cadeia dupla; ENA; antigénios nucleares solúveis; NMDA: N-metil-D-asparto; AMPA: ácido aminometilfosfónico; LGI: leucine-rich glioma inactivated

topiramato $100 \mathrm{mg}$ bid.

Cerca de duas semanas depois, o marido referia que a doente se tornara novamente mais desconfiada, acusando-o de manter relações extraconjugais com a sogra já falecida e com a própria irmã. Voltou a dirigir-se ao cemitério por diversas vezes, exigindo que o corpo da mãe fosse exumado para ser queimado "e deixar de me fazer mal" (sic). Recusava a toma da medicação antiepilética, acusando o marido de a querer envenenar. A família apercebeu-se que a doente tinha voltado a usar os mesmos produtos de ervanária. Este quadro motivou o recurso à Urgência Metropolitana de Psiquiatria do Porto, tendo sido internada compul- sivamente ao abrigo da Lei de Saúde Mental. Na admissão ao internamento, não apresentava alterações de relevo nos exames físico e neurológico. Ao exame psíquico, apresentava-se vígil, orientada no tempo, espaço e situação, com postura defensiva, desconfiada, com hostilidade latente. $\mathrm{O}$ humor era disfórico. Era constatável atividade delirante de ciúme e de envenenamento, e de teor místico "tenho de desenterrar a minha mãe e queimar o corpo, senão não tenho sossego" (sic). Identificavam-se, ainda, interpretações delirantes relativamente a eventos passados "a minha mãe não quis ir ao meu casamento porque já andava metida com o meu marido" (sic). Não se apurava atividade 
alucinatória. Não possuía crítica para o seu estado mórbido ou para a necessidade de tratamento. Na admissão, foi repetido o estudo complementar, que não demonstrou alterações (Tabela 3). Realizou-se ainda rastreio de deterioração cognitiva (mini-mental state examination, teste do relógio, Bateria de Lisboa para a Avaliação de Demência), o qual não sugeriu a presença de défices e avaliação da personalidade (Minnesota Multiphasic Personality Inventory-2) que mostrou elevação nas escalas de neuroticismo e de depressão. Após análise dos rótulos dos produtos adquiridos na ervanária, apurou-se a presença de extrato do fruto da árvore da castidade (Vitex agnus-castus), cogumelo Ganoderma lucidum, trevo vermelho, sabugueiro vermelho, rábano negro, cartilagem de tubarão e mexilhão lábio-verde. No internamento, suspendeu todos os produtos de ervanária e iniciou toma de risperidona em titulação até $2 \mathrm{mg} / \mathrm{dia}$. Após uma semana de internamento, a atividade delirante começou a desaparecer, e assistiu-se a uma adequação do comportamento, retomando o equilíbrio relacional a nível familiar. A doente desenvolveu crítica para as alterações anteriores, aceitando o tratamento, pelo que cessaram os pressupostos que haviam presidido ao seu internamento compulsivo, passando a regime voluntário de tratamento. Teve alta três semanas após a admissão. O antipsicótico foi retirado em consulta nos primeiros quatro meses após alta. Mantém, desde então, o acompanhamento por Psiquiatria não tendo voltado a apresentar sintomas psicóticos.

\section{DISCUSSÃO}

Este caso clínico evidencia duas manifestações possíveis de toxicidade cerebral: sintomas neurológicos e sintomas psiquiátricos. Na sequência de uso continuado de produtos de ervanária, iniciou-se quadro de alterações comportamentais associadas a disfunção fronto-temporal, incluindo atividade epileptiforme. Com a suspensão dos produtos, tanto os sintomas neurológicos como psiquiátri- cos remitiram. Após a doente ter reiniciado os mesmos produtos por sua iniciativa, o quadro neuropsiquiátrico reaparece, mas desta vez sem alterações eletroencefalográficas. A idade tardia, a ausência de antecedentes e a sua personalidade pré-mórbida não são sugestivas de psicose endógena. Entre os vários produtos, destaca-se a presença de extrato de Vitex agnus-castus. Esta planta tem propriedades moduladoras do eixo hipotálamo-hipófise-gónada e agonistas dos recetores D2 centrais ${ }^{10,11}$ e tem sido utilizada no tratamento da disforia pré-menstrual. Encontramos na literatura apenas uma outra descrição de um quadro psicótico em provável relação com o consumo de Vitex agnus- castus. $^{12}$

Neste caso, o uso continuado deste produto ou a interação com os restantes foi, provavelmente, a causa dos sintomas psicóticos inaugurais e bizarros que a doente apresentou, sendo o contexto da morte da mãe responsável pela patoplastia do delírio. A reversão dos sintomas e a ausência de novos episódios nos cinco anos de seguimento reforçam o diagnóstico de perturbação delirante orgânica de carácter iatrogénico.

Em idades tardias e em doentes sem antecedentes psiquiátricos, é premente investigação adicional que exclua a presença de possíveis causas exógenas. O uso de produtos sem prescrição médica deve ser sistematicamente questionado, dado raramente ser referido espontaneamente, como consequência da convicção de que se tratam de produtos desprovidos de efeitos laterais. É necessário melhor esclarecimento sobre o potencial dopaminérgico do Vitex agnus-castus.

\section{CONTRIBUTO DOS AUTORES}

ASM: Pesquisa de bibliografia relacionada com a situação clínica, avaliação da doente em Psiquiatria de ligação no internamento em Neurologia e acompanhamento da doente em consulta. Elaboração do artigo.

Tabela 3 - Estudo complementar efetuado no internamento em Psiquiatria

\begin{tabular}{|c|c|}
\hline Exame complementar & Resultado \\
\hline Eletroencefalograma & $\begin{array}{l}\text { Ritmo de base posterior, de baixa amplitude, irregular, sobretudo beta, sem evidente } \\
\text { reactividade à abertura-oclusão dos olhos. Não se evidenciou actividade epileptiforme ou } \\
\text { alterações focais. Conclusão: Registo de pouca qualidade com a doente pouco colaborante, } \\
\text { ritmo de base beta em relação provável com medicação psicotrópica/ansiedade. Não se } \\
\text { identificaram actividades anormais, designadamente epileptiformes. }\end{array}$ \\
\hline TC-CE & Sem alterações morfológicas. \\
\hline Hemograma & Normal. \\
\hline Bioquímica & $\begin{array}{l}\text { Função renal e hepática normal. lonograma (sódio, potássio, cloro, cálcio e fosfato) normal. } \\
\text { Marcadores inflamatórios negativos. }\end{array}$ \\
\hline Função tiroideia & Normal. \\
\hline Vitamina B12 & Normal. \\
\hline Ácido fólico & Normal. \\
\hline Serologias VIH, VHC, VHB & Negativas. \\
\hline Pesquisa de drogas de abuso na urina & Negativa para as substâncias testadas*. \\
\hline
\end{tabular}


ADA: Acompanhamento da doente. Pesquisa bibliográfica. Revisão crítica do artigo.

AS: Acompanhamento da doente no internamento. Revisão crítica do artigo.

RG: Avaliação da Psiquiatria de ligação no internamento de Neuro e acompanhamento em consulta. Revisão crítica do artigo.

\section{PROTECÇÃO DE PESSOAS E ANIMAIS}

Os autores declaram que os procedimentos seguidos estavam de acordo com os regulamentos estabelecidos

\section{CONFIDENCIALIDADE DOS DADOS}

Os autores declaram ter seguido os protocolos do seu centro de trabalho acerca da publicação de dados.

\section{CONSENTIMENTO DO DOENTE}

Obtido.

\section{CONFLITOS DE INTERESSE}

Os autores declaram a inexistência de conflitos de interesse na realização do presente trabalho.

\section{FONTES DE FINANCIAMENTO}

Este trabalho foi realizado sem contributo de subsídios ou bolsas

wort and ginseng. Psychiatry. 2005;2:56-61.

8. Minervini L, Romanini FA, Solmi M, Passamani A, Sferrazza E, Schifano F. Acute psychotic episode associated with the intake of a testosteroneenhancer herbal mixture purchased online. Psychother Psychosom. 2012;81:248-9.

9. Dickinson A, Blatman J, El-Dash N, Franco J. Consumer usage and reasons for using dietary supplements: report of a series of surveys. J Am Coll Nutr. 2014;33:176-82.

10. Meier B, Berger D, Hoberg E, Sticher O, Schaffner W. Pharmacologica activities of Vitex agnus-castus extracts in vitro. Phytomedicine. 2000;7:373-81.

11. Nasri S, Oryan S, Rohani AH, Amin GR. The effects of Vitex agnus castus extract and its interaction with dopaminergic system on $\mathrm{LH}$ and testosterone in male mice. Pak J Biol Sci. 2007;10:2300-7.

12. Firoozeh F, Omran D, Serge B. Drug-induced psychotic disorder after administration of Vitex agnus castus (chasteberry) medication to treat premenstrual syndrome: a case report. Arch Clin Psychiatry. 2019;46:80. 